that this will allow the machine to operate at higher frequencies, yielding faster acceleration and a smaller, and therefore potentially cheaper, facility than TESLA.

Another advantage of the NLC design is the technology's established track record. "We already have one at $50 \mathrm{GeV}$, so going to $500 \mathrm{GeV}$ is only a factor of 10 , and we have lots of experience," says Richter.

But the NLC concept received a blow in the past year, when researchers found physical deterioration in the copper cells after 1,000 hours of operation. "We should know by the summer if new designs will overcome these problems," says Steve Holmes, associate director at Fermilab.

More ominously, an initial 1999 cost estimate for the NLC came in at a politically unrealistic $\$ 7.9$ billion. "We need this to be reduced by $25 \%$, preferably by $50 \%$," says Peter Rosen, head of high-energy physics at the US Department of Energy. He says a potential reduction of $30 \%$ has already been achieved.

TESLA's use of superconducting resonators should mean a higher beam intensity and lower operating costs, its advocates say. Compared with the NLC, the radiofrequency devices that excite superconducting resonators are simpler to build. But the largest functioning accelerator using superconducting technology, the Thomas Jefferson National Accelerator Facility in Virginia, operates at only $1 \mathrm{GeV}$.

Albrecht Wagner, DESY's director, believes that the price estimate his team will publish on 23 March will be considered reasonable. But unlike the US estimate, it will exclude labour and operational costs, which could double the actual price.

The TESLA proposal will be assessed by the Wissenschaftsrat, Germany's science council, which will decide whether to recommend it to the government. German research minister Edelgard Buhlman has made positive noises about TESLA, but has said the project will go ahead only with the support of the international particle physics community - and financial support from abroad. But Wagner contends that construction could start within two years.

Political factors are likely to settle the choice of both the site and the design. The US community plans a major gathering of particle physicists in Snowmass, Colorado, this July to look at future priorities. A subpanel of the High Energy Physics Advisory Panel is meanwhile mapping out a 20 -year plan for the discipline.

With substantial funding allocated for building the LHC, Europe is not flush with money for a new collider either, and DESY is trying to promote TESLA as a multidisciplinary facility whose associated freeelectron laser will also be used by materials scientists, chemists and biologists.

\title{
More culls planned as Britain wrestles with foot-and-mouth
}

\section{David Adam, London}

Up to a million healthy farm animals are to be slaughtered in a fresh attempt to break the stranglehold of foot-and-mouth disease on the British countryside, the government announced last week.

All sheep and pigs within three-kilometre exclusion zones around areas of high infection will be culled. Government vets hope that the mass slaughter will create 'fire-walls' that the infection cannot cross.

Meanwhile, with more than 325 cases of the disease now reported, officials have admitted that attempts to contain the virus among animal herds that were infected before movement restrictions were introduced have failed.

"Some of the new cases we're seeing are down to contiguous infection, things like airborne spread, vehicle movement and people movement," says a spokesman for the Ministry of Agriculture, Fisheries and Food (MAFF).

But he denies that the outbreak is out of control, pointing out that new cases can still be traced back to animals infected during the original outbreak. "We're still saying that [the epidemic] is under control to a certain extent," he says.

But some experts disagree. "The crucial measure is if the transmission potential is self-sustaining," says Roy Anderson, a leading epidemiologist at Imperial College, London. Because each primary infection on a farm is leading to more than one secondary infection, he says, the situation "is quite clearly not under control".

Anderson agrees that the mass slaughter around infection hot-spots is "absolutely the right thing to do". But he is worried about whether other, more isolated cases can be effectively contained.

The epidemic, which broke out last month (see Nature 410, 4; 2001), is the first major outbreak in Britain since 1967. One reason why it has proven to be more difficult to control than the government had hoped is that some infected animals were sold in private deals at cattle markets, so the sales were never officially recorded and the animals could not be traced until their symptoms were observed.

Although the initial stages of any epidemic are the hardest to predict, epidemiologists remain optimistic about the possible control of the disease in mainland Europe. The first case of foot-and-mouth was confirmed in France last week. But France traced and slaughtered all animals that had been imported from Britain in the weeks preceding the initial outbreak, and placed herds

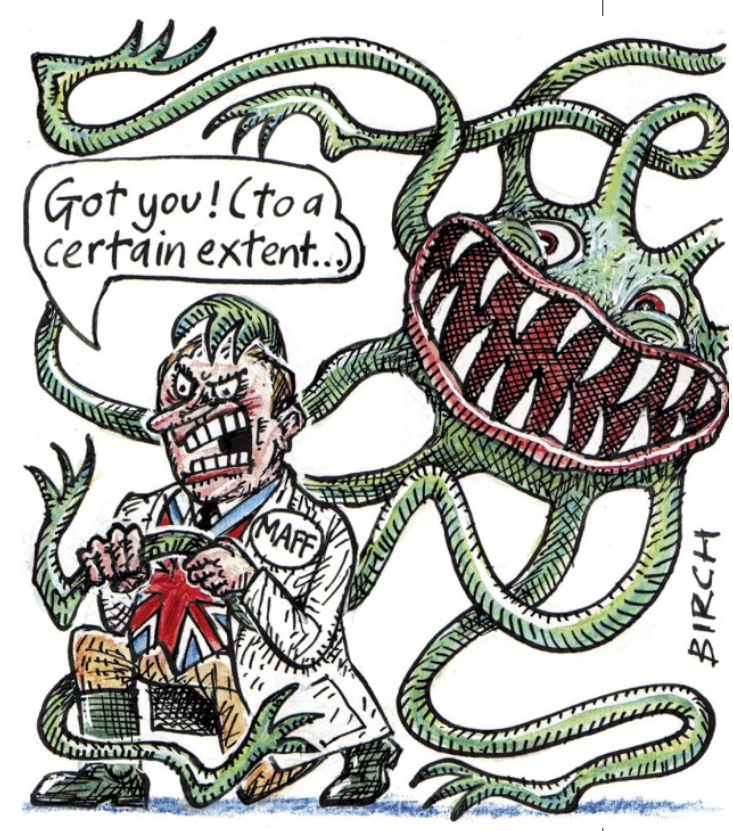

that may have been in contact with them under quarantine and close surveillance. The infected animal was found in one of these herds.

"The French have reacted very quickly and very well," Anderson says. "An epidemic is a non-linear process, therefore action taken in the early stages prevents far more cases than action taken later."

Mark Savay at the National Veterinary Centre in Paris adds that restrictions on animal meetings and transportation were introduced in France within days of the first UK case. "We received clear instructions from the European Commission to do that," he says, adding that other European Union countries would have received orders to do the same.

Controls on meat, livestock and milk imports from Britain, as well as animal movement restrictions, have been tightened in most other European countries. Countries outside Europe, including Japan and the United States, are also acting to keep the virus out, banning imports from Europe and introducing strict checks on travellers.

Vets and epidemiologists agree that modern patterns of animal movement and trade have increased the spread of the infection. It has already spread further in Britain than the 1967-1968 outbreak did in six months. "The number of animals moved and the number of journeys is not that different today but the distances involved are greater," says Chris Bostock, director of the government-funded Institute for Animal Health.

1 http://www.maff.gov.uk/animalh/diseases/fmd/ default.htm 